\section{(- OPEN ACCESS}

\title{
Primary pulmonary plasmacytoma presenting with rare IgG lambda monoclonal gammopathy
}

\author{
Yasmin Rahim, ${ }^{\oplus}$ Farrukh Zia Tareen, ${ }_{1}^{2}$ Rashida Ahmed, ${ }^{3}$ Javaid Ahmed Khan ${ }^{4}$
}

\begin{abstract}
${ }^{1}$ Department of Pulmonology and Critical Care, Aga Khan University, Karachi, Pakistan ${ }^{2}$ Department of Hematology and Oncology, Aga Khan University, Karachi, Pakistan

${ }^{3}$ Department of Pathology and Microbiology, Aga Khan University, Karachi, Pakistan ${ }^{4}$ Department of Pulmonary Medicine, Aga Khan University Hospital, Karachi, Pakistan
\end{abstract}

\section{Correspondence to} Dr Yasmin Rahim, yrahim80@hotmail.com

Accepted 15 February 2019

\section{SUMMARY}

Extramedullaryplasmacytoma (EMP) represents a peculiar and typically progressive malignancy that can originate outside the bone marrow. Primary pulmonary plasmacytoma (PPP) is a rare subset of EMP, confined to the lung. A 55-year-old man, diabetic, non-smoker presented to our clinic with a right chest wall swelling. A routine chest radiograph showed a well-circumscribed opacity in the right upper lung zone. A CT of the chest revealed a large right upper lobe mass with extensive local infiltration. Biopsy and immunohistochemical evaluation led to a diagnosis of PPP. Screening for multiple myeloma was negative. Serum immunofixation showed an IgG lambda monoclonal gammopathy, found in a minority of PPP patients. In view of disease extent, treatment with chemotherapy and radiotherapy was initiated. The patient is currently in out patient follow-up and has shown a favourable response to the treatment with a considerable decrease in serum lgG levels.

\section{BACKGROUND}

Plasma cell neoplasms can present as solitary (solitary plasmacytoma) or multiple lesions (multiple myeloma, MM). Solitary plasmacytomas occur most frequently in bone but on occasion they can also be found in soft tissues, termed extramedullary plasmacytomas (EMP). ${ }^{1}$ EMP constitutes 3\%-5\% of plasma cell tumours with a predilection for the upper aerodigestive tract. ${ }^{2-4} \mathrm{~A}$ primary pulmonary origin is an exceedingly rare occurrence, with a varied and non-specific clinical and radiological expression, presenting a diagnostic challenge to the clinician. By definition, patients with primary pulmonary plasmacytoma (PPP) do not develop osteolytic bone lesions, hypercalcaemia or renal

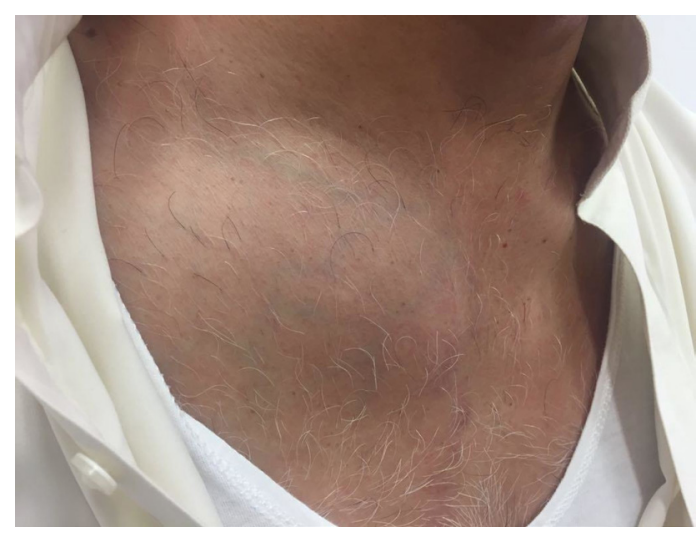

Figure 1 Right upper anterior chest wall swelling. failure. Serum M-proteins are seen in a minority of the cases with PPP, with a predominance of $\mathrm{IgG}$, Kappa (k) light chains. ${ }^{5}$ Guidelines on the management of EMP refer mainly to tumours located in the head and neck, these cannot be strictly applied to patients with PPP. ${ }^{6}$ Data regarding prognosis and risk of progression to $\mathrm{MM}$ is scant, rendering the long-term follow-up of such patients crucial. ${ }^{7}$ Here, we report a case of PPP with IgG lambda monoclonal gammopathy, followed by a brief review of the literature.

\section{CASE PRESENTATION}

A 55-year-old man, diabetic with no smoking history presented to us with pain, redness and swelling of his right upper anterior chest. There was an associated history of shortness of breath, backache, progressive generalised weakness and weight-loss over a 6 month period. Physical examination revealed a firm, non-tender swelling on the right side of his sternum (figure 1). On auscultation, breath sounds were not audible in the posterior upper chest. Clinical examination of the remaining organs and apparatuses was otherwise unremarkable.

\section{INVESTIGATIONS}

Laboratory investigations showed normal complete blood counts with haemoglobin $120 \mathrm{~g} / \mathrm{L}$, leucocyte count of $4.7 \times 10^{9} / \mathrm{L}$ with $51.2 \%$ neutrophils, $34.2 \%$ lymphocytes, and $11.8 \%$ monocytes and platelet count $205 \times 10^{9} / \mathrm{L}$. Blood chemistry values were all within normal limits, with a creatinine of $0.9 \mathrm{mg} / \mathrm{dL}$.

Chest radiograph showed a well-demarcated homogenous opacity in the right upper lung zone (figure 2). At this point, there was a high suspicion of a primary pulmonary malignancy and a CT scan of the chest was ordered to confirm or refute this suspicion. The CT scan showed a right upper lobe lobulated mass, $10.2 \times 8.8 \times 11.2 \mathrm{~cm}$ in size, anteriorly eroding the sternum and adjacent first rib, superiorly extending into the supraclavicular region with infiltration of the sternocleidomastoid, medially abutting the mediastinal vessels and superior vena cava with infiltration of the T1 vertebra and extension into the neural foramina at the T1-2 level with enlarged right hilar and pre-carinal lymph nodes (figure 3A,B). A CT-guided percutaneous needle aspiration biopsy of the mass showed linear cores of tissue exhibiting diffuse dense infiltration by plasmacytoid cells with moderate degree of nuclear atypia, which were strongly 


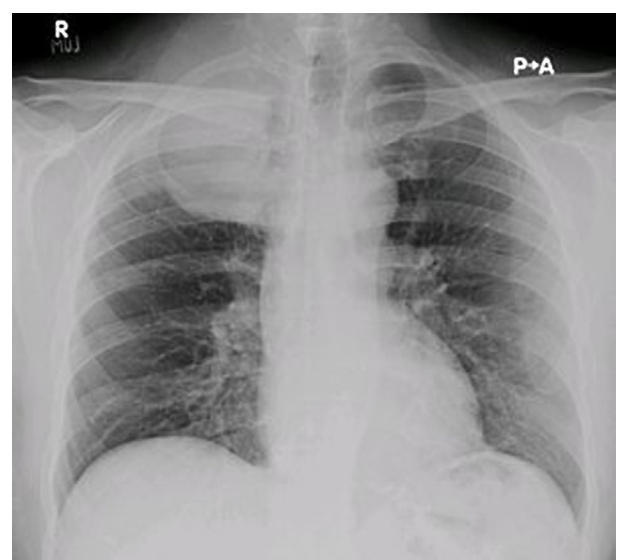

Figure 2 Chest X-ray showing right apical pulmonary opacity.

immunoreactive to MUM-1, CD138 and CD56 indicating a plasmacytoma (figure 4A-D). Serum immunofixation showed IgG lambda monoclonal gammopathy. Serum IgG, IgA and IgM levels were $70.47 \mathrm{~g} / \mathrm{L}, 1.26 \mathrm{~g} / \mathrm{L}$ and $0.66 \mathrm{~g} / \mathrm{L}$, respectively. Further work-up revealed normal levels of serum albumin, calcium, lactate dehydrogenase and uric acid. Serum B2 microglobulin level was $3551 \mathrm{ng} / \mathrm{mL}$. Further screening for MM with bone marrow biopsy and skeletal survey was negative. Concurrent cytogenetic and fluorescence in situ hybridization studies disclosed a normal karyotype with no aberrations.

\section{TREATMENT}

The patient was managed as a case of PPP with $\operatorname{IgG}$ lambda monoclonal gammopathy.

Taking into account, the size of the primary lesion along with extensive local infiltration, making complete surgical excision difficult, we planned radiotherapy and six cycles of chemotherapy, namely cyclophosphamide, bortezomib and dexamethasone.

\section{OUTCOME AND FOLLOW-UP}

The patient showed notable clinical improvement with reduction in IgG levels from $70.47 \mathrm{~g} / \mathrm{L}$ at presentation to $57.37 \mathrm{~g} / \mathrm{L}$, $48.39 \mathrm{~g} / \mathrm{L}, 15.13 \mathrm{~g} / \mathrm{L}$ and $12.02 \mathrm{~g} / \mathrm{L}$ at $4,8,20$ and 24 weeks of treatment, respectively, and a significant reduction in primary tumour size at 6 months follow-up.

Patients with PPP constitute a high-risk population for developing MM, warranting close follow-up. Our patient is being followed closely for any untoward outcomes.

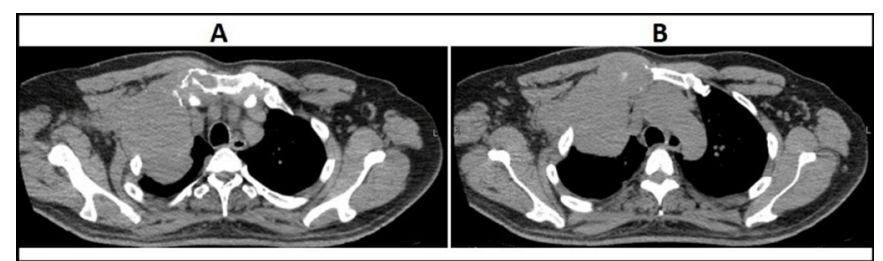

Figure 3 (A) CT scan of the chest (axial view) revealing right apical lobulated mass, $10.2 \times 8.8 \times 11.2 \mathrm{~cm}$ in size, anteriorly eroding the sternum and adjacent first rib. (B) CT scan of the chest (axial view) revealing right apical lobulated mass medially extending to the mediastinum and abutting the mediastinal vessels and superior vena cava.

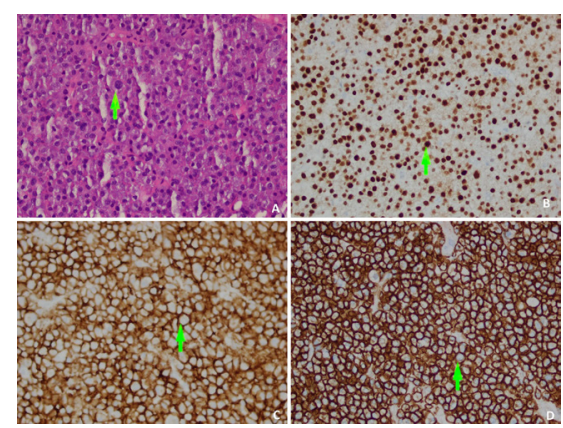

Figure 4 (A)H\&E stain $(40 \times 10)$ showing neoplastic plasma cells with pleomorphism (arrow) (B): Immunohistochemical (IHC) stain with MUM 1 protein, showing nuclear positivity in plasma cells $(40 \times 10)(C)$ : IHC stain with CD56 showing membranous positivity in neoplastic plasma cells $(40 \times 10)(D)$ : IHC stain with CD138 showing membranous positivity in neoplastic plasma cells $(40 \times 10)$.

\section{DISCUSSION}

EMP, are rare plasma cell tumours that arise outside the bone marrow, constituting $3 \%$ of the plasma cell malignancies. ${ }^{2} 3$ Eighty per cent of the cases involve the upper respiratory tract. Less frequent sites of involvement include the gastrointestinal tract, liver, lymph nodes, testis, skin and central nervous system. ${ }^{4}$

PPP are rare EMP located in the lung. In a review of 36 published cases of PPP, Stuppi et al reported a mean and median age of 57 and 58 years, respectively, consistent with prior reviews. ${ }^{5}$ Contrary to EMP of other sites a fairly even ratio of 1.3:1 was noted between men and women. ${ }^{8}$

The clinical manifestations of PPP are closely related to the tumour location and are variable. Accurate radiographic diagnosis is extremely difficult. Cumulative reports indicate that radiographic findings with PPP tend to be non-specific, with two patterns of growth observed: nodule/mass, with upper lobe predominance ${ }^{9}$ or pulmonary infiltrates ${ }^{10}$ with or without local lymph node involvement. Rarely, pleural involvement has also been reported. ${ }^{11}$ However, these findings are not specific and can also be seen in more common tumours including lung carcinoma, metastatic tumours, tuberculoma and hamartoma. Our patient presented with vague respiratory symptoms accompanied by pain, redness and swelling of the right anterior chest wall. Radiographically, the lesion was rounded, homogenous in density, with lobulated margins.

Based on a literature review of 19 previously published cases of PPP by Joseph et al, the presence of neoplastic cells in sputum cytology and bronchoscopy were noted to carry a poor diagnostic yield. Fine-needle aspiration or thoracotomy was often required for a definitive diagnosis. ${ }^{12}$

MM can also involve the lung and in order to differentiate it from PPP a systemic staging system including skeletal survey, bone marrow examination and immunoelectrophoresis of serum and urine are required to rule out systemic disease. ${ }^{13}$ Unlike MM, PPP can lack an associated M-protein in the serum or BenceJones light chains in urine. Their presence is however directly related to the tumour cell mass. Some speculate that the smaller tumour burden in EMP could explain the lower frequency of detection of M-proteins in the disease. ${ }^{14}{ }^{15}$ The development or disappearance of an M-protein and the magnitude of the M-protein level was seen to mirror tumour burden and hence clinical course. Koss et al reported IgG as the predominant M-protein with kappa $(\mathrm{k})$ light chain in a review of five cases of $\mathrm{PPP}^{5}$ To our knowledge, three other cases of PPP with IgG, lambda monoclonal gammopathy have been reported in literature. 91617 
There are no standard guidelines for the management of PPP, due to limited follow-up data on too few patients. Solitary PPP are best treated with anatomic pulmonary resection with or without radiotherapy. ${ }^{18}$ Joseph et al reported that radiotherapy and surgery carried an equal efficacy as treatment modalities. ${ }^{9}$ Adjuvant chemotherapy seems to have no particular benefit on control or progression to $\mathrm{MM}^{3}$ and it is usually reserved for patients with diffuse disease, aggressive histological forms and as a therapeutic alternative for patients with inoperable disease or poor local control after surgery or radiotherapy. ${ }^{19}{ }^{20} \mathrm{Nie} e t$ al reviewed one case of multiple lung nodules, three cases of diffuse pulmonary infiltration and one case of a tumour in each lung treated with combination chemotherapy, namely melphalan and prednisolone. ${ }^{72} 22$ In the past decade, bortezomib, an anti-angiogenic agent has emerged as a promising treatment for MM. ${ }^{23}{ }^{24}$ Recent reports have mentioned the efficacy of bortezomib for EMP or MM with plasmacytomas. ${ }^{25-28}$

Long-term survival in PPP remains unclear. Koss et al reported tumour dissemination to regional or distant lymph nodes, in a manner similar to lung carcinomas along with a $20 \%$ rate of progression to $\mathrm{MM} .^{5}$ In a recent literature review by Edelstein et al, a $40 \%$ rate of progression to MM was noted, necessitating serial quantification of M-protein after treatment of PPP. ${ }^{7}$

\section{Learning points}

- The presentation of primary pulmonary plasmacytoma (PPP) with IgG lambda monoclonal gammopathy is a rare and an unprecedented finding.

- PPP lacks specific clinical and radiographic features and therefore differentiating it from other, more common causes of lung masses, for example, primary lung cancer and rarely primary extranodal lymphoma and primary pulmonary sarcomas is prudent.

- Transthoracic needle aspiration or needle/core biopsy represent safe, effective and accurate modalities for diagnosing lung malignancies. They are becoming a strong alternative to surgical intervention.

- In general, anatomic pulmonary resection is the best treatment of PPP, while chemotherapy with or without radiotherapy may be a better choice in those with diffuse pulmonary involvement or widespread metastasis.

- Bortezomib represents a promising agent for extramedullary plasmacytoma or multiple myeloma with multiple plasmacytomas.

- Accrual of a large number of similar cases is needed in order to establish a standard therapeutic approach towards this condition.

Contributors This case report was a concept of JAK. YR with help from FZT wrote the manuscript under the supervision of JAK. RA provided the histopathology images. Critical revision of the manuscript was done by JAK. All authors read and approved the final manuscript.

Funding The authors have not declared a specific grant for this research from any funding agency in the public, commercial or not-for-profit sectors.

Competing interests None declared.

Patient consent for publication Not required.

Provenance and peer review Not commissioned; externally peer reviewed.

Open access This is an open access article distributed in accordance with the Creative Commons Attribution Non Commercial (CC BY-NC 4.0) license, which permits others to distribute, remix, adapt, build upon this work non-commercially, and license their derivative works on different terms, provided the original work is properly cited and the use is non-commercial. See: http://creativecommons.org/ licenses/by-nc/4.0/

\section{REFERENCES}

1 Weber DM. Solitary bone and extramedullary plasmacytoma. Hematology 2005:2005:373-6.

2 Dores GM, Landgren O, McGlynn KA, et al. Plasmacytoma of bone, extramedullary plasmacytoma, and multiple myeloma: incidence and survival in the United States, 1992-2004. Br J Haematol 2009:144:86-94.

3 Shih LY, Dunn P, Leung WM, et al. Localised plasmacytomas in Taiwan: comparison between extramedullary plasmacytoma and solitary plasmacytoma of bone. $\mathrm{Br} J$ Cancer 1995; 71:128-33.

4 Helling CA. Extramedullary plasma cell tumors as observed in various location. Arch Path 1943;36:95

5 Koss MN, Hochholzer L, Moran CA, et al. Pulmonary plasmacytomas: a clinicopathologic and immunohistochemical study of five cases. Ann Diagn Pathol 1998:2:1-11.

6 Soutar R, Lucraft H, Jackson G, et al. Guidelines on the diagnosis and management of solitary plasmacytoma of bone and solitary extramedullary plasmacytoma. $\mathrm{Br} J$ Haematol 2004:124:717-26.

7 Edelstein E, Gal AA, Mann KP, et al. Primary solitary endobronchial plasmacytoma. Ann Thorac Surg 2004:78:1448-9.

8 Meis JM, Butler JJ, Osborne BM, et al. Solitary plasmacytomas of bone and extramedullary plasmacytomas. A clinicopathologic and immunohistochemical study. Cancer 1987;59:1475-85

9 Wei S, Li X, Song Z, et al. Primary endobronchial plasmacytoma involving local lymph nodes and presenting with rare immunoglobulin $\mathrm{G}$ lambda monoclonal gammopathy. Can Respir J 2012;19:e28-30.

10 Kazzaz B, Dewar A, Corrin B. An unusual pulmonary plasmacytoma. Histopathology 1992;21:285-7.

11 Chen KT, Padmanabhan A. Pancoast syndrome caused by extramedullary plasmacytoma. J Surg Oncol 1983;24:117-8.

12 Joseph G, Pandit M, Korfhage L. Primary pulmonary plasmacytoma. Cancer 1993; 71:721-4.

13 Mohammad Taheri Z, Mohammadi F, Karbasi M, et al. Primary pulmonary plasmacytoma with diffuse alveolar consolidation: a case report. Patholog Res Int 2010;2010:1-3.

14 Medini E, Rao Y, Levitt SH. Solitary extramedullary plasmacytoma of the upper respiratory and digestive tracts. Cancer 1980;45:2893-6.

15 Bataille R, Sany J. Solitary myeloma: clinical and prognostic features of a review of 114 cases. Cancer 1981;48:845-51.

16 Chang CC, Chang YL, Lee LN, et al. Primary pulmonary plasmacytoma with immunoglobulin G/lambda light chain monoclonal gammopathy. J Thorac Cardiovasc Surg 2006;132:984-5.

17 Amin R. Extramedullary plasmacytoma of the lung. Cancer 1985;56:152-6.

$18 \mathrm{Kim} \mathrm{SH}$, Kim TH, Sohn JW, et al. Primary pulmonary plasmacytoma presenting as multiple lung nodules. Korean J Intern Med 2012;27:111.

19 Etienne G, Grenouillet M, Ghiringhelli C, et al. [Pulmonary plasmacytoma: about two new cases and review of the literature]. Rev Med Interne 2004;25:591-5.

20 Lacaze 0, Khaddage A, Court-Fortune I, et al. [Isolated intrapulmonary plasmacytoma; diagnostic and therapeutic difficulties]. Rev Mal Respir 2002;19:648-50.

21 Niitsu N, Kohri M, Hayama M, et al. Primary pulmonary plasmacytoma involving bilateral lungs and marked hypergammaglobulinemia: Differentiation from extranodal marginal zone B-cell lymphoma of mucosa-associated lymphoid tissue. Leuk Res 2005:29:1361-4

22 Horiuchi T, Hirokawa M, Oyama Y, et al. Diffuse pulmonary infiltrates as a roentgenographic manifestation of primary pulmonary plasmacytoma. Am J Med 1998; 105:72-4.

23 Richardson PG, Sonneveld P, Schuster MW, et al. Bortezomib or high-dose dexamethasone for relapsed multiple myeloma. N Engl J Med 2005;352:2487-98.

24 Richardson PG, Sonneveld P, Schuster M, et al. Extended follow-up of a phase 3 trial in relapsed multiple myeloma: final time-to-event results of the APEX trial. Blood 2007; 110:3557-60.

25 Pantelidou D, Tsatalas C, Margaritis D, et al. Successful treatment of lymph node extramedullary plasmacytoma with bortezomib. Ann Hematol 2006;85:188-90.

26 Chim CS, Ooi GC, Loong F, et al. Side effects and good effects from new chemotherapeutic agents. Case 3. Bortezomib in primary refractory plasmacytoma. $J$ Clin Oncol 2005:23:2426-8.

27 Laura R, Cibeira MT, Uriburu C, et al. Bortezomib: an effective agent in extramedullary disease in multiple myeloma. Eur J Haematol 2006;76:405-8.

28 Hughes M, Micallef-Eynaud P. Bortezomib in relapsed multiple myeloma complicated by extramedullary plasmacytomas. Clin Lab Haematol 2006;28:267-9. 
Copyright 2019 BMJ Publishing Group. All rights reserved. For permission to reuse any of this content visit https://www.bmj.com/company/products-services/rights-and-licensing/permissions/

BMJ Case Report Fellows may re-use this article for personal use and teaching without any further permission.

Become a Fellow of BMJ Case Reports today and you can:

- Submit as many cases as you like

- Enjoy fast sympathetic peer review and rapid publication of accepted articles

Access all the published articles

- Re-use any of the published material for personal use and teaching without further permission

For information on Institutional Fellowships contact consortiasales@bmjgroup.com

Visit casereports.bmj.com for more articles like this and to become a Fellow 